\title{
DA POLÍTICA DE ACESSO À LUTA PELA PERMANÊNCIA: CONTRIBUIÇÕES DO PAIETS AOS INDÍGENAS E QUILOMBOLAS NA UNIVERSIDADE
}

\author{
DE LA POLÍTICA DE ACCESO A LA LUCHA POR LA PERMANENCIA: \\ CONTRIBUCIONES DEL PAIETS A LOS INDÍGENAS Y QUILOMBOLAS EN LA \\ UNIVERSIDAD
}

\section{FROM ACCESS POLICY TO FIGHTING FOR PERMANENCE: CONTRIBUTIONS OF PAIETS TO INDIGENOUS AND QUILOMBOLAS AT UNIVERSITY}

\author{
AMARAL, Marcel Jardim \\ amaral.marcel@yahoo.com \\ FURG - Universidade Federal do Rio Grande \\ https://orcid.org/0000-0003-0712-7357 \\ PEREIRA, Vilmar Alves \\ vilmar1972@gmail.com \\ FURG - Universidade Federal do Rio Grande \\ http://orcid.org/0000-0003-2548-5086
}

\begin{abstract}
RESUMO Os órgãos de educação muito recentemente estão se adaptando para a inclusão de indígenas e quilombolas no contexto universitário através de ações afirmativas prevendo o ingresso desses sujeitos aos cursos das mais diversas áreas. Nesta conjuntura, estaria à universidade preparada para receber a diversidade que estes trazem, bem como comprometer-se com a valorização cultural e saberes que cada membro dessas comunidades possui, para que estes desiguais não venham a optar por uma possível evasão? Este artigo tem por objetivo tracejar breve relato referente a gêneses do subprograma de Auxílio ao Ingresso nos Ensinos Técnico e Superior, denominado PAIETS Indígena e Quilombola, bem como expor as estratégias criadas com foco no enfrentamento das problemáticas que surgem a partir do ingresso das comunidades tradicionais no ensino superior.
\end{abstract}

Palavras-Chaves: Indígenas. PAIETS. Permanência. Quilombolas.

RESUMEN Los órganos de educación muy recientemente se adaptan para la inclusión de indígenas y quilombolas en el contexto universitario a través de acciones afirmativas previendo el ingreso de estos sujetos a los cursos de las más diversas áreas. En esta coyuntura, ¿estaría a la universidad preparada para recibir la diversidad que éstos traen, así como comprometerse con la valorización cultural y los saberes que cada miembro de estas comunidades posee, para que estos desiguales no vengan a optar por una posible evasión? Este artículo tiene por objetivo disuadir brevemente relato referente a génesis del subprograma de Auxilio al ingreso en las Enseñanzas Técnico y Superior, denominado PAIETS Indígena y Quilombola, así como exponer las estrategias creadas con foco en el enfrentamiento de las problemáticas que surgen a partir del ingreso de las comunidades tradicionales en la enseñanza superior.

Palabras Claves: Indígenas. PAIETS. Permanencia. Quilombolas. 


\title{
Atos de Pesquisa em Educação - ISSN 1809-0354 \\ Blumenau, v.14, n.2, supl.1, p.841-857, out./nov. 2019 \\ DOI: http://dx.doi.org/10.7867/1809-0354.2019v14n2s1p841-857
}

\begin{abstract}
The education agencies very recently are adapting themselves to the inclusion of natives and quilombolas in the university context through affirmative action's foreseeing the entrance of these subjects to the courses of the most diverse areas. At this juncture, would the university be prepared to receive the diversity they bring, as well as commit themselves to the cultural appreciation and knowledge that each member of these communities has, so that these unequal ones will not opt for a possible evasion? The purpose of this article is to provide a brief account of the genesis of the subprogram of Assistance to Admission to Technical and Higher Education, called PAIETS Indigene and Quilombola, as well as exposing the strategies created with a focus on addressing the problems that arise from the entry of traditional communities in higher education.
\end{abstract}

Keywords Indigenous. PAIETS. Permanence. Quilombolas.

\section{PRIMEIRAS PALAVRAS}

Partindo da compreensão de que as necessidades econômicas e políticas caminham juntas com a educação formal e que o Brasil é um país com forte desigualdade social e racial, existem implicações constantes no que se refere às lutas sociais dos diferentes grupos para o direito ao acesso as políticas públicas.

Os pobres, os idosos, a juventude, as mulheres, os negros, a comunidade LGBTI $^{1}$, as comunidades tradicionais e os grupos populacionais e específicos ${ }^{2}$ não cessam de lutar diuturnamente pelos mínimos direitos sociais, em especial o acesso à educação formal visando o "ser mais". Aliás, não são estes os sujeitos que com o desenvolver de suas trajetórias após o processo de conscientização despertam para a humanização e transformação do mundo que os cerca?

A existência humana é que permite, portanto, denúncia e anúncio, indignação e amor, conflito e consenso, diálogo ou sua negação com a verticalidade de poder. Grandeza ética se antagonizando com as mazelas antiéticas. É exatamente a partir dessas contradições que nascem os sonhos coletivamente sonhados, que temos as possibilidades de superação das condições de vida a que estamos submetidos como simples objetos para tornar-nos todos e todas seres mais (FREIRE, 2001, p. 14).

\footnotetext{
${ }^{1}$ Lésbicas, gays, bissexuais, travestis, transexuais e pessoas intersex.

2 O autor deste artigo entende como grupos populacionais e específicos: os extrativistas, os pescadores, as comunidades de terreiro, as famílias assentadas da reforma agrária, ribeirinhas, agricultores familiares, beneficiários do programa nacional do crédito fundiário, famílias acampadas, famílias atingidas por empreendimentos de infraestrutura, famílias de resgatados do trabalho análogo e/ou escravo, catadores de material reciclável e as famílias de presos do sistema carcerário.
} 
Acontece que os saberes das experiências feitas e a aceitação destes socialmente construídos não aparentam ser bem-vindos ao universo acadêmico. É evidente que esta não aceitação dos diferentes no processo educacional está diretamente relacionada ao imaginário historicamente construído pelo capitalismo de que as universidades e as instituições de ensino são exclusivas aos sujeitos privilegiados no Brasil e no mundo. Para o educador popular Jaime José Zitkoski (2011):

No atual contexto latino-americano o embate colocado para o campo da esquerda e, portanto, para as forças políticas progressivas é a luta contra a hegemonia neoliberal e, igualmente, a construção de alternativas a esse projeto que está levando à barbárie o mundo todo (ZITKOSKI, 2011, p. 12).

O empreendedorismo e as privatizações vêm se colocado na atual conjuntura como resposta à ascensão social a qualquer custo, implicando o sistema ambiental para o fortalecimento do neoliberalismo. O incentivo à lamentável reforma do ensino médio no Brasil e a formação tecnicista para o mercado do trabalho são características presentes no cenário brasileiro ainda mais fortes no "pós-golpe"3 à democracia no mês de agosto do ano de 2016, com o impeachment da Presidenta Dilma Vana Rousseff. Vale relembrar, que esta teve o mandado presidencial executado de 2011 até o ano de 2016, não concluindo o período determinado por lei, visto o processo acima exposto.

Sabe-se que, no governo do então preso político ${ }^{4}$ Luiz Inácio Lula da Silva, o Brasil vivenciou um processo de inúmeras vitórias populares que historicamente nunca foram cogitadas, como a inclusão de cotas sociais e raciais no ensino superior. Também houve inacreditável expansão dos Institutos e Universidades Federais, das bolsas relacionadas ao estudo e financiamento estudantil através do ProUni ${ }^{5}$ e Fies ${ }^{6}$.

\footnotetext{
${ }^{3} \mathrm{O}$ autor relaciona o termo "pós-golpe" referindo-se ao processo de impeachment, sofrido pela primeira mulher eleita presidenta do Brasil, através do voto popular, cito: Dilma Vana Roussef, que foi afastada da presidência, haja visto a acusação de "pedaladas fiscais"; ato este, praticado por todos os presidentes anteriores sem quaisquer punições, já que não configura crime.

${ }^{4}$ A expressão "preso político", usada aqui, traz a concepção de que o julgamento a Luis Inácio Lula da Silva teria assimilações ao tribunal de exceção. Além disso, anterior ao julgamento o ex-presidente manifestou o desejo de candidatar-se novamente à presidência da república, onde realizou dura crítica ao judiciário brasileiro e por consequência teve o pedido de "habeas corpus" negado em todas as instâncias.

${ }^{5}$ Programa Universidade para Todos.

${ }^{6}$ Fundo de Financiamento ao Estudante do Ensino Superior.
} 
Ainda que de forma tímida já tivessem sido realizados alguns estudos sobre essas políticas reparatórias pelos tucanos ${ }^{7}$, no governo do Fernando Henrique Cardoso (1995-2003) com o Partido da Social Democracia Brasileira - PSDB, foi apenas na gestão Lula (2003-2010) que essas demandas passaram a ser enfrentadas. Pode-se afirmar então que antes do Partido dos Trabalhadores - PT assumir a Presidência da República do país, a concretização e a implementação das ações afirmativas para o povo e as comunidades tradicionais eram, de certa forma, utopias por parte dos movimentos sociais populares e envolvidos.

Os impactos e as consequências que essas políticas trouxeram às comunidades tradicionais podem ser analisados em especial na área de educação, pois só a partir daí houve, no Brasil, o maior acesso dos indígenas e quilombolas ao ensino superior. Destaca-se que anterior à chegada desses sujeitos na Universidade Federal do Rio Grande - FURG, o Programa de Auxílio ao Ingresso nos Ensinos Técnico e Superior - PAIETS visava apenas o cuidado aos sujeitos de baixa renda com o pré-universitário popular, incentivando o acesso destes sujeitos aos cursos ofertados pela FURG.

Com a inclusão dos diferentes por meio de processo seletivo específico para as comunidades tradicionais, foi necessário voltar-se a esses grupos também no que tange à permanência e à conclusão do curso. O presente artigo enfoca a trajetória do ingresso dos indígenas e quilombolas advindos dessas comunidades à FURG, bem como explicita estratégias criadas para a permanência destes com a criação de um subprograma voltado a esta parcela da academia, projetada pelo PAIETS através da demanda que surgiu ao longo dessa trajetória.

\section{O PAIETS ENQUANTO QUILOMBO: ESPAÇO DE LUTA, REFÚGIO E RESISTÊNCIA!}

O surgimento do estado moderno, e a constante luta dos movimentos sociais populares nos mais distintos grupos esclarecem as constantes contradições que vivemos ainda hoje. Se de um lado, todos são iguais, por que nem todos possuem

\footnotetext{
${ }^{7}$ O Partido da Social Democracia Brasileira - PSDB traz como símbolo a ave tucano; devido a isso todos os filiados ao partido já citado, tem como adjetivação o termo "tucano".
} 


\section{Atos de Pesquisa em Educação - ISSN 1809-0354 \\ Blumenau, v.14, n.2, supl.1, p.841-857, out./nov. 2019 \\ DOI: http://dx.doi.org/10.7867/1809-0354.2019v14n2s1p841-857}

seus direitos garantidos? Todos os homens nascem livres e iguais perante a lei, mas na prática nem tanto. Ao mesmo tempo em que o Brasil afirma ser um país de todos, existem inúmeras leis e decretos que tratam do direito e cidadania dos mais diversos grupos denominados minorias pelo país.

No Brasil, até hoje, um pequeno número de unidades familiares desfruta de inúmeros privilégios e detêm o poder e o controle da classe operária. Muito embora todos os sujeitos estejam inseridos no sistema capitalista, nem todos estão em condições precárias de vida ou de exclusão. Os sinais da desigualdade perseveram ao longo dos séculos evidentes em toda a parte do mundo. O contraste entre pobres e ricos, homens e mulheres, negros, indígenas e brancos são evidenciados todos os anos através das estatísticas e os meios de comunicação do país.

Os trabalhadores rurais e urbanos advindos das unidades familiares de baixa renda ou que estejam inseridos na extrema pobreza são cotidianamente atacados pelo sistema perverso do capital, em todos os setores da sociedade. Sabe-se desde então que em sua grande maioria são estes que se matriculam na educação básica municipal e estadual; quando não marcados pela evasão diante as constâncias de vida que se apresentam no dia pós dia destes sujeitos. Apesar desse sistema completamente desigual e desmotivador para a classe operária, o patrono da educação brasileira, incentiva a massa de trabalhadores e trabalhadoras a não conformar-se, pois:

\footnotetext{
[...] os sonhos são projetos pelos quais se luta. Sua realização não se verifica facilmente, sem obstáculos. Implica, ao contrário, avanços, recuos, marchas às vezes demoradas. Implica luta. Na verdade a transformação do mundo a que o sonho aspira é um ato político e seria uma ingenuidade não re-conhecer que os sonhos têm seus contra-sonhos. É o momento de que uma geração faz parte, porque histórico, revela marcas antigas, que envolvem compreensão da realidade, interesse de grupos, de classes, preconceitos, gestação de ideologias que se vêm perpetuando em contradição com aspectos mais modernos (FREIRE, 2000, p. 54).
}

A educação bancária e a estratificação social reforçam o dualismo entre o educar para o mundo do trabalho e o treinar para o mercado que de forma intencional visa atender aos interesses da elite. Nesta perspectiva, o Programa de Auxílio ao Ingresso nos Ensinos Técnico e Superior - PAIETS surge no ano de 2007 na Universidade Federal do Rio Grande - FURG, objetivando a transformação da 
realidade e crendo que a escola não pode mais perseverar com as características da sociedade desigual em que está inserida. Trata-se de um programa que na concepção freireana de ensino e carisma no viés da Educação Popular percebeu a ausência das minorias na universidade, bem como a essência destas questões em pauta, além da necessidade da diferenciação dos diversos grupos.

Muito além dos funcionalistas e marxistas, este programa acredita piamente na transformação do espaço universitário por meio do ingresso dos advindos de classe popular e/ou do recorte de gênero, raça ou credo com a inserção desses excluídos no ensino superior, pois "quem ensina aprende ao ensinar, e quem aprende ensina ao aprender" (FREIRE, 1996, p. 23).

Entende-se, portanto que estes sujeitos não aceitos no universo elitista acadêmico poderão ter a possibilidade de formação para o mundo do trabalho ou pesquisa, através de seu ingresso na universidade. Para isso, inúmeros acadêmicos que acreditam nos impactos deste programa (PAIETS), ministram práticas educativas nas diversas áreas de conhecimento, nos inúmeros bairros da cidade e fora dela, para auxiliarem estes pré-acadêmicos no processo seletivo do Exame Nacional do Ensino Médio - ENEM, portanto:

[...] o desejo expresso pela multidão que se mobiliza nos cursos prévestibulares populares mostra-se como uma potência que pode transformarse em luta organizada e constituinte pela universalização do direito à educação e pela democratização do conhecimento e da produção do conhecimento (NASCIMENTO, 2007, p. 84).

Nesta linha de pensamento, com a intencionalidade de que os cidadãos oriundos da classe popular venham a ingressar no ensino superior e fortalecer a luta pela inclusão dos diferentes com a possibilidade de ser educando de uma universidade pública e de qualidade, visa-se à transformação radical destes espaços. Para o comunista Hobsbawm (2015):

[...] o que leva às pessoas a posição revolucionária consciente não é a ambição de seu objeto, mas o fracasso aparente de todas as formas alternativas para alcançá-lo, o fechamento de todas as portas para elas. Se nos deixarem fora de nossa casa com a porta fechada perceberemos que há várias maneiras de entrar nela, embora algumas impliquem uma confiante paciência. Somente quando nenhuma delas parece realista pensamos em arrombar a porta. Entretanto, vale a pena observar que mesmo assim provavelmente não arrombaremos a porta a menos que tenhamos a sensação de que vai ceder. Tornar-se um revolucionário encerra não só uma 


\section{Atos de Pesquisa em Educação - ISSN 1809-0354 \\ Blumenau, v.14, n.2, supl.1, p.841-857, out./nov. 2019 \\ DOI: http://dx.doi.org/10.7867/1809-0354.2019v14n2s1p841-857}

dose de desesperança, mas também de alguma esperança (HOBSBAWM, 2015, p. 318-319).

Neste sentido, vale ressaltar que muitos dos educadores-educandos pertencentes ao PAIETS são os mesmos sujeitos que anteriormente procuravam inscrever-se no programa em busca da objetivação da aprovação no curso desejado na universidade, e após a aprovação do ENEM, retornaram para contribuir através da práxis no decorrer das atividades e execução do programa. De acordo com Freire e Shor (1986, p. 47) "a educação libertadora deve ser compreendida como um momento, ou um processo ou uma prática onde estimulamos as pessoas a se mobilizar ou a se organizar para adquirir poder".

A partir deste horizonte, os membros do PAIETS trazem a convicção de que muito além da extensão universitária, contribuem de forma significativa nos bairros em que aquele contexto do programa está inserido para a execução das atividades. $\mathrm{A}$ emancipação dos sujeitos em Paulo Freire revela que as conquistas políticas na educação só podem perseverar de forma concreta se houver a práxis humana como centro das lutas sociais para uma educação como prática da liberdade. Dessa forma, temos a compreensão de que:

[...] o conhecimento deve ser trabalhado nos cursinhos populares a partir do estabelecimento de relações humanas em uma perspectiva horizontal, ou seja, que privilegia a troca de vivências entre os envolvidos nos projetos (educandos, educadores, organizadores, comunidade), tendo em vista as trajetórias de cada ente envolvido. Os próprios espaços informais nas comunidades ou mesmo nas escolas onde funcionam os pré-vestibulares servem para o tensionamento das hierarquias comumente observadas na relação pedagógica, além de outro fator que também se verifica não raramente: a indiferença com o outro (LEIPNITZ; PEREIRA, 2008, p. 109).

Neste contexto, o Programa de Auxílio ao Ingresso nos Ensinos Técnicos e Superior - PAIETS emerge como o movimento social popular que organizado por educador popular e educandos já ingressos na universidade, veem a instituição como um direito de todos/as. Tendo por objetivo proporcionar espaços de discussões e de ensino/aprendizagem que torne o acesso ao ensino superior mais próximo das 
 \\ Blumenau, v.14, n.2, supl.1, p.841-857, out./nov. 2019 \\ DOI: http://dx.doi.org/10.7867/1809-0354.2019v14n2s1p841-857}

necessidades dos segmentos sociais que historicamente foram e ainda hoje perseveram sendo invisíveis aos olhos do estado.

\section{A NECESSIDADE DE UM PAIETS ESPECÍFICO PARA INDÍGENAS E QUILOMBOLAS}

Partindo da ideia de que não basta incluir o índio e o quilombola na universidade, mas é de extrema relevância voltar-se para a sua permanência na instituição de ensino, este subprograma tem como característica primordial a proposta de integração com os estudantes indígenas e quilombolas que ingressaram na FURG. O subprograma traz por objetivo geral oferecer situações de favorecimento da aprendizagem através de escuta e ensinagem, contribuindo significativamente no acesso e permanência dos estudantes advindos de comunidades tradicionais para esta instituição de ensino.

As comunidades quilombolas são grupos carregados de identidade e histórias, baseadas na cultura própria do qual se situa, formando-se por meio do processo histórico no Brasil pouco difundido que começou nos primórdios da escravidão no país. Hoje, esses povos tradicionais simbolizam mais do que resistência, em especial nesses tempos temerosos em que vivenciamos no século XXI, é preciso mais do que nunca, preservar costumes e culturas trazidos pelos antepassados, para 0 fortalecimento biopsicossocioambiespiritual ${ }^{8}$.

Já os saberes e culturas das comunidades indígenas, ao contrário do imaginário social, não se encontram estagnados e/ou atrasados com o tempo. Existem atualmente no Brasil mais de 224 povos indígenas e cada comunidade possui especificidades e formas de viver, além das diferentes culturas e histórias, o que vem confirmar a diversidade de nosso país. Os direitos desses grupos sociais foram garantidos pela Constituição Federal brasileira do ano de 1988, pelo Decreto

\footnotetext{
${ }^{8}$ Terminologia adotada recentemente por Pereira (2016) em Ecologia Cosmocena onde as dimensões integradoras do ser humano (biológicas, psicológicas, sociológicas, ambientais e espirituais) não são pensadas de formas individuais, compondo assim um único sentido e relação.
} 
4.887/2003 e pelo Decreto 6.040/2007. A autora Jodas (2012), destaca O protagonismo dos indígenas nestas pautas:

É importante evidenciar a articulação do movimento indígena a partir deste período na defesa de seus direitos já que foram diretamente responsáveis por mobilizar grande parte das mudanças ocorridas na legislação, especialmente a partir da constituição federal de 1988 (JODAS, 2012, p. 34).

É evidente que a Constituição Federal de 1988 foi protagonista de um marco histórico da sociedade brasileira, no que tange os mínimos sociais e que garantir o direito a terra desses grupos significa diretamente a não violação da existência desses e de sua cultura, embora para Ávila (2017, p. 98) seja "importante pontuar que os sujeitos que criam dispositivos legislativos para o estado brasileiro são em sua grande maioria homens brancos". Ou seja, para a autora os sujeitos que conduziram a política do Brasil desde 1988 fazem parte de grupos privilegiados com interesses próprios e não coletivos. A autora destaca ainda que:

As pessoas negras e indígenas que não detinham poder econômico algum e que não transitassem pelos ideais culturais civilizatórios estavam de alguma forma à margem do processo. Isso não significa dizer que não existiram políticas públicas para sujeitos marginalizados, mas que as mesmas foram desenvolvidas através de estratégias assimilatórias, inferiorizantes e tutelares como ocorreu com as populações originárias. Se o status jurídico da tutela, para a população indígena, acabou em 1988, a população negra percebeu a condição de liberta em 1888 , mas para ambas as populações 0 imaginário que pretende subordiná-las ainda está presente (ÁVILA, 2017, p. 97).

Para a historiadora, todo o contexto histórico provocado desde o passado, atinge diretamente 0 presente desses sujeitos, bem como reafirma a ideia de inferioridade que foi projetada e é concretizada no cotidiano desses sujeitos que ainda hoje lutam por dignidade no país. Tanto as comunidades quilombolas quanto as indígenas, vivem até hoje as transformações próprias da realidade social brasileira do qual estão inseridas, portanto, mesmo com mudanças superficiais, esses sujeitos nunca irão abandonar a referência e o respeito à sua história e aos antepassados. Além disso, existe como ponto comum entre estes: a luta pelo respeito, a afirmação 
de suas identidades culturais, construção da cidadania diferenciada, as políticas públicas especificas, bem como a resistência da garantia de suas terras.

No que tange tantas lutas historicamente acima citadas, o PAIETS INDÍGENA E QUILOMBOLA se apresenta como proposta de educação popular emancipadora de sujeitos que vivem em condições de opressão e preocupados com o acesso e permanência ao ensino superior. Essa proposta originou-se de inúmeras experiências decorrentes do primeiro processo seletivo de estudantes indígenas desta instituição de ensino superior, pelo Programa de Ação Inclusiva - PROAI no ano de $2010 \mathrm{com}$ o ingresso de dois indígenas, pertencentes à tribo Kaingang, que ingressaram nos cursos de Enfermagem e Medicina.

A divulgação do processo seletivo para indígenas foi na época realizada juntamente com a Fundação Nacional do Índio - FUNAI para as aldeias do estado, onde na ocasião foram ofertadas cinco (05) vagas que foram disponibilizadas e distribuídas para os cursos de Medicina, Enfermagem, Ciências Biológicas Licenciatura, Direito e Letras/Português. No ano de 2011 foram ofertadas mais cinco (05) vagas mantendo a oferta para os mesmos cursos do ano anterior onde ingressaram na FURG três (03) indígenas sendo dois da comunidade Kaingang para os cursos de Medicina e Enfermagem e um (01) indígena da comunidade Guarani para o curso de Direito.

No entusiasmo e efervescência dessa política de ações afirmativas hora garantida, e a felicidade de educadores progressistas com o ingresso desses sujeitos, foi necessário repensar seus direitos, para que pudessem perseverar nos cursos em que os líderes das comunidades escolhem para cada um. Haja visto que, a universidade incluiu-os, mas não havia pensado e/ou projetado sobre as constantes dificuldades para a permanência destes e a conclusão do curso do qual ingressou. Portanto, vê-se a necessidade da sensibilidade do olhar para os diferentes:

Temos o direito a sermos iguais quando a diferença nos inferioriza. Temos o direito a sermos diferentes quando a igualdade nos descaracteriza. As pessoas querem ser iguais, mas querem respeitadas suas diferenças. Ou 


\section{Atos de Pesquisa em Educação - ISSN 1809-0354 \\ Blumenau, v.14, n.2, supl.1, p.841-857, out./nov. 2019 \\ DOI: http://dx.doi.org/10.7867/1809-0354.2019v14n2s1p841-857}

seja, querem participar, mas querem também que suas diferenças sejam reconhecidas e respeitadas. (SANTOS, 2003, p. 458)

Além do preconceito sofrido pela oposição universitária, esses indígenas advindos de sua comunidade de forma tão rápida com a política de cotas passavam a ter a saúde mental abalada, pois haviam se afastado brutalmente dos seus familiares, passando a residir na urbanização e turbulência da cidade, refletindo de forma significativa no desempenho acadêmico. Além disso, alguns indígenas não falavam e nem escreviam a língua portuguesa, o que causava desânimo e direcionava-os a evasão.

Nessa perspectiva, era necessário focar em oferecer o apoio pedagógico aos estudantes indígenas que tinham se deslocado para a Universidade, incentivando a permanência e a qualidade de suas trajetórias acadêmicas evitando a evasão dos mesmos. Partindo dessa realidade, e visando a amenização do impacto cultural, foi criado pela Pró-reitoria de Assuntos Estudantis - PRAE o Programa de Apoio Pedagógico e Permanência aos Acadêmicos Indígenas - PAPPAI, hoje denominado Programa de Acompanhamento ao Acadêmico Indígena: "Ag Juna ke" (ajudar) - PAAI "Ag Juna ke".

No ano seguinte, já com o auxílio PAAI - Ag Juna Ke manteve-se o processo de seleção e o número de vagas contemplando os cursos de História-licenciatura, Enfermagem, Sistemas de Informação, Psicologia e Medicina. Neste respectivo processo seletivo ingressaram três (03) acadêmicos, sendo um indígena da comunidade Pankará para Medicina, um da comunidade Guarani para Psicologia e outro da comunidade Kaingang para o curso de Enfermagem.

Estabelecido o diálogo durante essa trajetória, foi possível perceber algumas lacunas no processo, visto que não bastava apenas inclui-los nos cursos de bacharelado ou licenciatura da Universidade, mas definir políticas específicas para a permanência desses indígenas. Na ocasião, foi firmada a parceria entre o PAAI - Ag Juna Ke e o PAIETS.

Analisado o contexto, foi realizada intervenção emancipadora com esses sujeitos advindos de comunidades indígenas com o objetivo de reforço de suas identidades e saberes, bem como a contribuição das disciplinas com que estes apresentavam maiores dificuldades. Também no ano de 2012 os educadores 


\section{Atos de Pesquisa em Educação - ISSN 1809-0354 \\ Blumenau, v.14, n.2, supl.1, p.841-857, out./nov. 2019 \\ DOI: http://dx.doi.org/10.7867/1809-0354.2019v14n2s1p841-857}

populares voltaram-se para as demandas das comunidades quilombolas, com a intencionalidade de incluí-los no processo seletivo.

Apresentado o relatório que foi elaborado pelo Programa Comunidades FURG/COMUF foram descobertas a presença de comunidades quilombolas reconhecidas pela Fundação Cultural Palmares nos trinta e um (31) territórios na região do ecossistema costeiro. Inclusive, foram descobertas comunidades negras rurais que estavam em processo de reconhecimento na época, como por exemplo, o recente quilombo da cidade do Rio Grande - RS denominado "Macanudos" que se localiza na "Quintinha", periferia da região.

Em homenagem ao quilombo, os estudantes negros e negras da FURG intitularam o coletivo que fazem parte com o nome da comunidade quilombola. Além desse grupo de estudantes, o Coletivo Camaleão, que discute pautas no âmbito de diversidade sexual e identidade de gênero, também acompanhou essa importante caminhada.

A partir do ano de 2013 esses coletivos passaram a compor o PAIETS INDIGENA E QUILOMBOLA visando à promoção de ações que propagassem a acolhida e a autoestima destas comunidades tradicionais. Desde então membros das comunidades quilombolas também passaram a ingressar na universidade por meio de processo seletivo específico, que da mesma forma que os indígenas, se constitui com uma prova diferenciada tratando-se de questões de português, interpretação de texto e redação.

Diante os fatos acima citados, o PAIETS passou a prestar auxílio e acolhida também aos estudantes quilombolas. $\mathrm{O}$ objetivo principal dessa proposta referiu-se à troca de saberes, vivências e acompanhamento de sujeitos indígenas e quilombolas que chegaram por meio de processo seletivo específico para comunidades tradicionais à FURG. Essas aprendizagens com os sujeitos visam até hoje à promoção contínua de emancipação que permitam aos educandos e educadores reconhecer suas trajetórias e perceber que sua permanência nesses espaços de conquistas também é uma forma de resistência as suas condições históricas de opressão.

No mesmo ano ingressaram cinco quilombolas (05) em que os cursos disponibilizados foram Direito, Enfermagem, História-licenciatura, Medicina e Psicologia. Já no ano de 2014 ingressaram oito (08) membros de comunidades 
quilombolas sendo disponibilizados novos cursos como: Educação Física, Agroecologia, Engenharia de Alimentos e Pedagogia. Entre o ano de 2015 e o ano de 2016 entraram vinte (20) quilombolas e dezenove (19) indígenas sendo disponibilizados novos cursos, como: Ciências Contábeis e Engenharia Mecânica, além do curso de Licenciatura em Educação do Campo.

Se por um lado as lideranças quilombolas e indígenas lutam para que parte de seus membros possam concluir o ensino superior e retornar à comunidade tradicional para contribuir com os seus; de outro lado, existe forte receio por parte destes de que a "academia branca" transmita aos cotistas valores do capitalismo, vindo então a fragilizar seu retorno ao território. Além disso, observado o ingresso, foi explícito que, com o passar do ano letivo, algumas dificuldades dos indígenas e quilombolas na permanência dos cursos em que foram incluídos, começaram a surgir de forma mais grave.

Sendo a questão financeira uma dessas dificuldades, a Secretaria de Educação Continuada, Alfabetização, Diversidade e Inclusão do Ministério da Educação - MEC criou, para a amenizar o problema, a Bolsa Permanência, em que esses estudantes advindos de comunidades tradicionais passaram a receber uma bolsa no valor de $R \$$ 900,00 (novecentos reais). Porém, apesar do acesso ao espaço universitário com a política de cotas ter sido fortalecida com essa remuneração para a permanência, o choque cultural não é solucionado com aporte financeiro.

Outra problemática nesse processo que se percebe de forma muito enraizada, se trata do corpo docente; pois esses educadores não recebem mínima formação na maior parte das universidades para acolher indígenas e quilombolas dentro da educação formal e, por vezes, não há quaisquer vontades desses para a transformação da realidade. Neste sentido concordamos com Freire (2001) que:

O grande problema do educador não é discutir se a educação pode ou não pode, mas é discutir onde pode, como pode, com quem pode, quando pode; é reconhecer os limites que sua prática impõe. É perceber que o seu trabalho não é individual, é social e se dá na prática social de que ele faz parte. É reconhecer que a educação, não sendo a chave, a alavanca da transformação social, como tanto se vem afirmando, é, porém, indispensável à transformação social. É reconhecer que há espaços possíveis que são políticos, há espaços institucionais e extras institucionais a serem ocupados pelas educadoras e pelos educadores cujo sonho é transformar a realidade injusta que aí está, para que os direitos possam começar a ser conquistados e não doados (FREIRE, 2001, p. 98-99). 
 \\ Blumenau, v.14, n.2, supl.1, p.841-857, out./nov. 2019 \\ DOI: http://dx.doi.org/10.7867/1809-0354.2019v14n2s1p841-857}

Além disso, é notável o estereótipo de que o aluno cotista não possui capacidade intelectual mínima para a conclusão do curso, que parte não apenas dos professores, mas também dos educandos na sala de aula. Nesta perspectiva esse subprograma proporciona também espaços de discussões e relatos de experiências para melhorar a relação fraterna, bem como o fortalecimento dessas comunidades. Acredita que a educação abranja muitos sentidos, além da conciliação dos saberes tradicionais destes povos e a academia, e da valorização cultural, tendo em vista que a diversidade pode contribuir para a transformação do sistema que já está posto desde sua gênese.

\section{CONSIDERAÇÕES FINAIS}

O respeito ao diferente nem sempre é colocado no centro do cotidiano do espaço universitário. A taxação de culturas supostamente inferiores à do branco prevalece na academia e o pluralismo cultural não é tido na maioria das vezes como positivo. A universidade que a educação popular almeja trata-se de um espaço onde os valores pré-estabelecidos sejam repensados e a partir de então haja o diálogo entre os diferentes, provocando assim tensões, dúvidas e conflitos que resultem em uma metodologia de trabalho incorporada à realidade dos excluídos do processo educacional.

O PAIETS enquanto programa é um ambiente de aconchego aos indígenas e quilombolas calouros e veteranos, onde podem confiar no subprograma para a possível amenização e/ou solução dos desafios que serão enfrentados diante a academia ainda hoje excludente. Conforme Arroyo

certamente a escola não é importantíssima por ser um passaporte ou chave para tudo; ela é importantíssima porque somos sujeitos de direito e temos direito ao conhecimento, ao saber, a formação, ao trabalho, e isso é outra lógica. (ARROYO, 2011, p. 124).

Através do ingresso dos indígenas e quilombolas no ensino superior se concretiza que estes estão diretamente ligados a concepção de Educação Popular, especificamente quando se trata das práticas educativas desenvolvidas em extensão pelo PAIETS - FURG. Atualmente são organizadas reuniões semanais, grupos de 
estudos fechados para indígenas e quilombolas, encontros gerais mensais, apresentações culturais que valorizam os saberes que estes trazem das comunidades, diálogos com as pró-reitorias envolvidas, a prefeitura municipal da cidade do Rio Grande que disponibiliza o acesso as Secretarias Municipais e o setor de Direitos Humanos da própria universidade.

Percebe-se de imediato que apesar da oposição universitária, os indígenas e os quilombolas distantes de suas comunidades, se fortalecem por meio de seus coletivos, bem como pelo próprio subprograma do PAIETS, que são espaços que possibilitam o fortalecimento dos elos para além das salas de aula e do ensino superior tão excludente, mesmo que com as ações afirmativas. Os gestores da Universidade Federal do Rio Grande aprendem todos os anos com os sujeitos advindos dessas comunidades, buscando assim a superação das dificuldades e o ingresso de novos indígenas e quilombolas nos cursos de graduação e pós-graduação, não apenas visando a inclusão, mas constantemente nas estratégias para as suas permanências.

\section{MARCEL JARDIM AMARAL}

Assistente Social, Mestre em Educação/PPGEdu e Doutorando em Educação Ambiental/PPGEA pela Universidade Federal do Rio Grande - FURG. Pesquisador do Grupo de Estudos sobre Fundamentos da Educação Ambiental e Popular GEFEAP.

\section{VILMAR ALVES PEREIRA}

Professor, Doutor em Educação/PPGEdu pela Universidade Federal do Rio Grande do Sul - UFRGS e Mestre em Educação/PPGEdu pela Universidade de Passo Fundo - UPF. Bolsista de Produtividade em Pesquisa do CNPq - Nível 2. Pesquisador do Instituto de Educação/IE. Membro do corpo docente do Programa de Pós-Graduação em Educação Ambiental/PPGEA do qual é coordenador e também membro do corpo docente do Programa de Pós-Graduação em Educação/PPGEDU ambos pela Universidade Federal do Rio Grande - FURG. Líder do Grupo de Estudos sobre Fundamentos da Educação Ambiental e Popular - GEFEAP e Editor Chefe da Revista Eletrônica do Mestrado em Educação Ambiental - REMEA.

\section{REFERÊNCIAS}

ARROYO, M. G.. Currículo, território em disputa. Petrópolis, RJ: Vozes, 2011. 
ÁVILA, L. dos S.. Ações afirmativas e as relações étnico-raciais: análise sobre os processos seletivos específicos de estudantes indígenas e quilombolas da Universidade Federal do Rio Grande-FURG. Rio Grande: FURG, 2017.

BRASIL. Constituição (1988). Constituição da República Federativa do Brasil. Brasília, DF, Senado Federal: Centro Gráfico, 1988.

BRASIL. Decreto no 4.887, de 20 de novembro de 2003. Diário Oficial da República Federativa do Brasil, Brasília, DF, 20 de novembro de 2003.

BRASIL. Decreto № 6.040, de 07 de fevereiro de 2007. Diário Oficial da República Federativa do Brasil, Brasília, DF, 07 de fevereiro de 2007.

FREIRE, P.. Pedagogia da autonomia: saberes necessários à prática educativa. São Paulo: Paz e Terra, 1996.

FREIRE, P... Pedagogia da Indignação: cartas pedagógicas e outros escritos. São Paulo: Ed. UNESP, 2000.

FREIRE, P.. Política e educação: ensaios. 5. ed. São Paulo: Cortez, 2001.

FREIRE, P.; SHOR, I.. Medo e ousadia: o cotidiano no professor. 10. ed. Trad. Adriana Lopez. Rio de Janeiro: Paz e Terra, 1986.

HOBSBAWM, E.. Revolucionários: ensaios contemporâneos. 5. ed. São Paulo: Paz e Terra, 2015.

JODAS, J.. Entre a diversidade e a diferença: o programa de Ações Afirmativas da UFSCAR e as vivências dos estudantes indígenas. São Carlos: UFSCAR, 2012.

LEIPNITZ, L.; PEREIRA, T. L. A prática pedagógica no Cursinho Popular da ONGEP: aproximações com a pedagogia de Paulo Freire. In: MELLO, M. (Org). Paulo Freire e a Educação Popular: reafirmando o compromisso com a emancipação das classes populares. Porto Alegre: IPPOA/ATEMPA, 2008.

NASCIMENTO, A. Os cursos pré-vestibulares populares como prática de ação afirmativa e valorização da diversidade. In: BRAGA, M. L. S.; SILVEIRA, M. H. V. (Orgs.). O programa Diversidade na Universidade e a construção de uma política educacional anti-racista. Brasília: Secretaria de Educação Continuada, Alfabetização e Diversidade; UNESCO, 2007.

PEREIRA, V. A.. Ecologia Cosmocena: a redefinição do espaço humano no cosmos. Juiz de Fora, MG: GARCIA Edizioni, 2016.

SANTOS, B. S. de. Reconhecer para libertar: os caminhos do cosmopolitismo multicultural. Rio de Janeiro: Civilização Brasileira, 2003. 
Atos de Pesquisa em Educação - ISSN 1809-0354

Blumenau, v.14, n.2, supl.1, p.841-857, out./nov. 2019

DOI: http://dx.doi.org/10.7867/1809-0354.2019v14n2s1p841-857

ZITKOSKI, J. J. (Org.). Educação Popular e Prática Emancipatória: Desafios Contemporâneos. Porto Alegre, RS: CORAG, 2011.

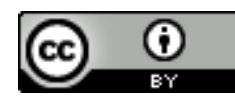

Esta obra está licenciada com uma Licença Creative Commons Atribuição 4.0 Internacional 